\title{
PATRIMÔNIO, NEGOCIAÇÃO E CONFLITO
}

Gilberto Velho

Quando eu era membro do Conselho do Patrimônio Histórico e Artístico Nacional, tive a oportunidade e o privilégio de ser o relator, em 1984, do tombamento do terreiro de candomblé Casa Branca, em Salvador, Bahia. Era a primeira vez que a tradição afro-brasileira obtinha o reconhecimento oficial do Estado Nacional. Creio que rememorar alguns episódios ligados a essa iniciativa pode ajudar a refletir sobre a dinâmica e as transformações do patrimônio cultural.

Na época, o secretário de cultura do MEC era o Dr. Marcos Vinicios Vilaça, que presidia também o conselho da SPHAN e que desempenhou um papel fundamental para o sucesso do tombamento. O Conselho encontravase bastante dividido. Vários de seus membros consideravam desproposital e equivocado tombar um pedaço de terra desprovido de construções que justificassem, por sua monumentalidade ou valor artístico, tal iniciativa. Cabe lembrar que, até aquele período, o estatuto do tombamento vinha sendo aplicado, basicamente, a edificações religiosas, militares e civis da tradição luso-brasileira. As primeiras principais medidas de legitimação e proteção ao patrimônio foram tomadas, sobretudo, em relação a prédios coloniais e, em menor proporção, aos do período do Império e da Primeira República.

O terreiro de Casa Branca apresentava uma tradição de mais de 150 anos e, com certeza, desempenhava um importante papel na simbologia e no imaginário dos grupos ligados ao mundo do candomblé e aos cultos afro-brasileiros em geral. Do ponto de vista dessas pessoas o que importava era a sacralidade do terreno, o seu "axé". Em termos de cultura material, encontrava-se um barco, importante nos rituais, um modesto casario, além da presença de arvoredo e pedras associados ao culto dos orixás. Não era nada que pudesse se assemelhar à Igreja de São Francisco em Ouro Preto, aos profetas de Aleijadinho em Congonhas, em Minas Gerais, ao Mosteiro 
de São Bento, ao Paço Imperial da Quinta da Boa Vista ou à Fortaleza de Santa Cruz, no Rio de Janeiro. Tratava-se, sem dúvida, de uma situação inédita e desafiante.

Fui designado para ser o relator devido à minha condição de antropólogo, naquela época chefe do Departamento de Antropologia do Museu Nacional e que acabara de encerrar o meu mandato de presidente da Associação Brasileira de Antropologia. Valorizei a importância da contribuição das tradições afro-brasileiras para o Brasil como um todo. Chamei a atenção, particularmente, para a dimensão das crenças religiosas dessas tradições que, inclusive, extrapolavam as suas fronteiras formais. Defini cultura como um fenômeno abrangente que inclui todas as manifestações materiais e imateriais, expressas em crenças, valores, visões de mundo existentes em uma sociedade. Afirmei "que no momento em que existe uma preocupação em reconhecer a importância das manifestações culturais das camadas populares, há que se reconhecer o candomblé como um sistema religioso fundamental à constituição da identidade de significativas parcelas da sociedade brasileira" ${ }^{1}$.

Destaquei tratar-se de "um fato social, um terreiro em plena atividade, com seus fiéis, sacerdotes e ritual em pleno dinamismo". Ao recomendar o tombamento, considerei fundamental chamar a atenção para o fato de que "o acompanhamento e a supervisão da SPHAN deve, mantendo seus elevados padrões, incorporar uma postura adequadamente flexível diante desse fenômeno religioso" e, ainda, que "o tombamento deve ser uma garantia para a continuidade da expressão cultural que tem em Casa Branca um espaço sagrado". Afirmei que a sacralidade, no entanto, não era sinônimo de imutabilidade e que a SPHAN não abriria mão da seriedade de suas normas, mas deveria "procurar uma adequação para lidar com o fenômeno social em permanente processo de mudança".

Concluí recomendando "o tombamento de todo o sítio, uma área de aproximadamente $6.800 \mathrm{~m}^{2}$, com as edificações, árvores e principais objetos sagrados, acompanhado de todas as medidas necessárias que efetivamente garantam a segurança desse patrimônio". Assinalei a visão de autores como Gilberto Freyre e Roger Bastide, que analisaram e valorizaram essa contribuição. Apontei também para o papel crucial na área da sociabilidade e do convívio dentro das camadas populares e entre estas e outros segmentos sociais. Frisei que, pelo menos, desde Nina Rodrigues ficara evidente o importante espaço social e simbólico ocupado pelos terreiros de Candomblé, entre os quais Casa Branca aparecia com particular destaque. A vida da cidade de Salvador não poderia ser compreendida sem essa percepção. Por outro lado, procurei demonstrar que dentro do quadro heterogêneo e complexo das 
grandes cidades contemporâneas, a atividade religiosa, com seus rituais e crenças, é essencial para a construção e a dinâmica das identidades.

Os membros do Conselho da SPHAN que discordavam dessa posição tinham suas convicções honestas e arraigadas, produto de décadas de práticas voltadas para um outro tipo de política de patrimônio. Argumentou-se também que não era possível tombar uma religião. Quase todos os presentes na reunião de Salvador concordavam que era necessário proteger o terreiro, mas alguns insistiam em não se utilizar a figura do tombamento ${ }^{2}$. É interessante registrar que um número considerável de conselheiros não compareceu à reunião. Entre esses sete ausentes certamente estavam vários opositores à medida de tombamento.

Havia dúvidas também quanto à situação legal do terreno ocupado por Casa Branca. O próprio prefeito de Salvador, presente à reunião, enviou uma nota à presidência afirmando que a posse do terreno pelo terreiro de Casa Branca estava assegurada pela prefeitura. Houve intenso debate com prós e contras. Como já disse, alguns dos argumentos contrários tinham suas razões e explicações a partir do que vinha sendo feito até então. No entanto, não posso evitar mencionar que em alguns casos poderia haver um certo desprezo pelo que considerávamos importantes manifestações culturais da nação brasileira.

É inegável que para a vitória do tombamento foi fundamental a atuação de um verdadeiro movimento social com base em Salvador, reunindo artistas, intelectuais, jornalistas, políticos e lideranças religiosas que se empenharam a fundo na campanha pelo reconhecimento do patrimônio afro-baiano. Havia um verdadeiro choque de opiniões que não se limitava internamente ao Conselho da SPHAN. Importantes veículos da imprensa da Bahia manifestaramse contra o tombamento que foi acusado, com maior ou menor sutileza, de demagógico. É importante rememorar esses fatos, pois a vitória foi muito difícil e encontrou fortíssima resistência. Foi necessário um esforço muito grande de um grupo de conselheiros, do próprio secretário de cultura do MEC e de setores da sociedade civil para que afinal fosse obtido sucesso.

A histórica sessão do Conselho realizou-se nos imponentes salões da Santa Casa da Misericórdia, em Salvador, com a presença de um público altamente mobilizado e emocionado. Na abertura da reunião estava presente o próprio Cardeal Primaz do Brasil, Dom Avelar Brandão. A votação final foi muito disputada, com três votos a favor do tombamento, um pelo adiamento, duas abstenções e um voto contra, expressando o grau de dificuldade encontrado para implementar a medida. O tombamento foi comemorado com grande alegria e júbilo pela maioria do público presente, mas não podia ocultar as fortes diferenças de opinião e pontos de vista. 
O caso do tombamento de Casa Branca poderia ser analisado como um drama social nos termos de Victor Turner (1974). Havia um grupo de atores bem definido com opiniões e mesmo interesses não só diferenciados mas antagônicos em torno de uma temática que se revelava emblemática para a própria discussão da identidade nacional. Independentemente de aspectos técnicos e legais, o que estava em jogo era, de fato, a simbologia associada ao Estado em suas relações com a sociedade civil. Tratava-se de decidir o que poderia ser valorizado e consagrado através da política de tombamento. Reconhecendo a válida preocupação de conselheiros com a justa implementação da figura do tombamento, hoje é impossível negar que, com maior ou menor consciência, estava em discussão a própria identidade da nação brasileira. A rápida passagem do Cardeal Primaz na histórica reunião não disfarçava que os setores mais conservadores do catolicismo baiano e, mesmo nacional, viam com maus olhos a valorização dos cultos afro-brasileiros.

Quando conselheiros argumentavam que não se podia "tombar uma religião", certamente entendiam que o tombamento de centenas de igrejas e monumentos católicos teria se dado apenas por razões artístico-arquitetônicas, o que não nos parecia correto. Assim, o tombamento de Casa Branca significava a afirmação de uma visão da sociedade brasileira como multiétnica, constituída e caracterizada pelo pluralismo sociocultural. Não há dúvida de que tal medida de reconhecimento do Estado representava também uma reparação às perseguições e à intolerância manifestadas durante séculos pelas elites e pelas autoridades brasileiras contra as crenças e os rituais afro-brasileiros (ver Maggie 1993).

Nesse episódio, a cidade de Salvador foi o locus do embate cuja repercussão atingia toda a sociedade nacional. Depois, não só outros terreiros foram tombados, mas diversos monumentos e construções ligadas a outras tradições que não a luso-brasileira também foram reconhecidos, como uma casa de colono, no Rio Grande do Sul, uma casa de chá japonesa, em São Paulo e, mais recentemente, através da valorização da cultura imaterial, rituais indígenas como o Quarup.

Essas diferenças e divergências devem-se às próprias características da sociedade complexa moderno-contemporânea com seus múltiplos segmentos, categorias, estratos e a heterogeneidade de suas diversas tradições culturais. Um dos problemas fundamentais que afetam e caracterizam a grande cidade contemporânea quando se trata de proteção, preservação e patrimônio é a questão imobiliária. No próprio caso de Casa Branca, havia interesse da indústria de construção civil na ocupação de seu terreno. Essa pressão de ocupação do solo urbano, até certo ponto inevitável no desenvolvimento do capitalismo, é o centro das principais dificuldades e polêmicas 
na política de proteção e preservação cultural e ambiental. Mas não se trata simplesmente de satanizar as empresas imobiliárias na sua voracidade insaciável que já infligiu danos irreversíveis às cidades brasileiras, destruindo ou desfigurando parte considerável de seu patrimônio natural e cultural. É sempre muito difícil impor limites à indústria de construção civil, que se constitui em um dos principais mercados para a mão-de-obra mais barata das camadas populares.

Por outro lado, é sempre muito delicado, como sabemos, lidar com medidas de políticas públicas que atinjam setores da sociedade civil. As queixas e as reclamações de moradores de cidades grandes e pequenas em relação às limitações impostas pelo tombamento de bens imóveis exigem atenção permanente no tocante a essas decisões e à sua implementação. Também que se constatem os desencontros e os impasses entre os órgãos federais, estaduais e municipais. Registro, por exemplo, o conflito entre a política federal de patrimônio e os interesses políticos de prefeitos que, freqüentemente, apresentam projetos de intervenção urbana que contrariam as orientações da antiga SPHAN, atual IPHAN. Lembro-me de outros casos que ocorreram no período em que era membro do Conselho, quando prefeitos de cidades históricas mineiras desejavam e, em alguns casos, conseguiram erguer construções que feriam agudamente áreas tombadas e seu entorno, como estádios de esportes, praças com repuxos coloridos, estações rodoviárias, entre outros. Essas obras, com maior ou menor transparência, representavam aspirações e interesses de autoridades e grupos empresariais, contando, às vezes, com o conquistado apoio de parte da população.

Um dos exemplos mais expressivos da problemática do crescimento impulsionado pela indústria de construção civil em confronto com preocupações preservacionistas é o de Copacabana. O início do desenvolvimento do bairro se dá com a abertura do Túnel Velho, em 1892, ligando-o ao bairro de Botafogo. Como escrevi em trabalho anterior:

Anteriormente, sua ocupação era rarefeita, com população de pescadores, algumas chácaras, casario esparso, uns poucos caminhos e ruas precárias. Seu desenvolvimento foi, no entanto, rápido com a expansão da capital republicana. Novas ruas, obras públicas, ampliação das linhas de bonde estimularam o crescimento demográfico com a multiplicação de áreas residenciais e de estabelecimentos comerciais. Já na década de 20, é um bairro importante da cidade, tendo os fortes de Copacabana e do Leme (atual Duque de Caxias) como marcos-limite da praia, e o recém-inaugurado Copacabana Palace como símbolo de afluência, prestígio internacional e de promissor turismo (Velho 1999:11). 
PATRIMÔNIO, NEGOCIAÇÃO E CONFLITO

O ritmo de ocupação do bairro vai se acelerando e, com a tecnologia dos elevadores e do concreto armado, transforma-se no primeiro bairro brasileiro a ser ocupado predominantemente por edifícios de mais de oito andares. Sua população cresce, chegando a ultrapassar 200 mil habitantes nos anos 1960, para posteriormente declinar. Esse exemplo envolve contradições e paradoxos da vida urbana. Copacabana é vendida como um paraíso à beiramar, com bela praia, paisagem privilegiada e ar saudável. Nos primeiros anos de sua ocupação, o clima chega a ser alardeado como atração em termos de saúde e bem-estar. Casas são derrubadas até restarem poucas nos anos 1970 e antigos prédios menores também são substituídos por construções mais modernas e elevadas. As suas características de bairro predominantemente residencial alteram-se com o desenvolvimento de intenso e variado comércio, assim como de várias atrações culturais e de lazer, como cinemas, teatros, galerias de arte, boates, casas de show etc.

Copacabana passa a ser, juntamente com seus atrativos naturais originais, locus privilegiado da sociedade de consumo do Rio de Janeiro e mesmo do Brasil. Poderíamos dizer que o seu apogeu se dá entre o final da Segunda Grande Guerra (1945) e meados dos anos 1970. Já nos anos 1950, sobretudo a partir do governo Juscelino Kubitschek, com a onda de desenvolvimento que atinge o país, novas mudanças vão alterar a situação social do bairro. O crescimento do consumo e a mobilidade social geram novas aspirações e expectativas de estilos de vida. De início, são principalmente famílias de camadas médias que têm como projeto mudar-se para Copacabana (ver Velho 1973 e 1999). Vêm de outras partes da cidade, da própria Zona Sul, do Centro, da Zona Norte e depois mesmo dos subúrbios. Boa parte dos novos moradores origina-se de outros estados, além dos estrangeiros que, desde o princípio, viam em Copacabana um bairro de sua predileção.

A condição do Rio de Janeiro como capital da República, antigo Distrito Federal até 1960, levava a que ali viessem morar políticos, burocratas e técnicos, de um modo ou de outro ligados ao Estado Nacional. São numerosos os casos de pessoas que, tendo ido morar no Rio de Janeiro para ocuparem funções ou cargos temporários, instalaram-se na cidade definitivamente com suas famílias. Copacabana foi durante muitos anos o bairro preferencial desses setores sociais mais ou menos elitizados. Acrescente-se a estes o pessoal do corpo diplomático e os representantes de grandes empresas internacionais. A famosa "princesinha do mar" tornou-se um lugar feérico, com uma vida noturna intensa que apresentava várias opções e alternativas para gostos os mais variados. Por exemplo, além da fama de suas mulheres bonitas, fartamente propagandeadas, o bairro tornou-se também um importante centro gay (ver Guimarães 2004 [1977]). 
Esse esplendor trazia com ele os próprios germes da deterioração. Copacabana foi super ocupada, construída e desgastada. A muralha de prédios erguidos sem preocupações e critérios urbanísticos bloqueou em grande parte a paisagem e afetou o clima, fazendo com que a diferença de temperatura entre a Avenida Atlântica e as ruas situadas no interior do bairro pudesse chegar a mais de 3 graus. A abundância de transporte, característica valorizada pelos aspirantes a moradores, contribuiu, juntamente com o aumento generalizado de automóveis, para agravar a poluição, além de produzir grandes engarrafamentos, barulho e desconforto.

Um dos fatos mais decisivos para as transformações no bairro foi a construção de grandes prédios de pequenos apartamentos de sala e quarto ou conjugados. Vão abrigar uma população mais modesta, em grande parte de inquilinos, que sacrificam espaço residencial para poderem viver no bairro que tem transporte, atende ao consumo e produz, de acordo com as representações dominantes, prestígio social (ver Velho 1973). Esse tipo de prédio, por suas características em quantidade e heterogeneidade de ocupantes, é muitas vezes palco de confrontos e tumultos. Muitos deles passam a ser malvistos e estigmatizados, como o notório Barata Ribeiro 200, que originou até uma peça de teatro (ver Velho 1971). Assim, há um progressivo declínio social dos moradores do bairro acompanhado de um envelhecimento de sua população.

Atualmente, Copacabana é o bairro do Brasil com a mais elevada proporção de idosos. Estes são os que chegaram nos anos 40, 50 e 60 do século $\mathrm{XX}$ e que optaram por permanecer por diversas razões. A maioria, apesar da insegurança e da violência crescentes, valoriza o relativo conforto ainda oferecido através de farmácias, postos médicos, clínicas, comércio em geral, além das possibilidades de lazer oferecidas pela praia, reforçada pelo calçadão construído no início dos anos 1970. Há também aqueles que não têm recursos para dali saírem e tentarem morar em locais de nível social comparável à Copacabana do passado.

Certamente a Zona Sul do Rio de Janeiro ocupa uma posição especial no imaginário não só da cidade mas do país como um todo, e mesmo internacionalmente. Copacabana foi durante algumas décadas o centro principal dessas representações. Apesar de sua relativa decadência, ainda é uma atração importante para vários tipos de turismo, assim como para boa parte dos moradores da cidade e do estado do Rio de Janeiro. De qualquer forma, é inegável a grande mudança que ocorreu desde o "paraíso à beira-mar" até a situação atual de caos urbano, prédios deteriorados, população de rua, comércio ilegal e as várias formas de violência. Constitui-se, portanto, um caso interessante para pensarmos sobre a problemática mais geral da cidade e 
dos patrimônios. Inegavelmente, do ponto de vista da arquitetura mais consciente, do planejamento urbano mais responsável, do preservacionismo e do ambientalismo, Copacabana é um símbolo poderoso do erro, do equívoco, do que não poderia ter sido feito e permitido. Foi gerada, inclusive, a categoria copacabanização, como sinônimo de desleixo e pilhagem urbanos.

Por outro lado, não há como ignorar que uma dimensão fundamental do que ocorreu no famoso bairro foi produto da busca de uma qualidade de vida melhor por parte de setores diferenciados da sociedade, de início mais elitizados e progressivamente cada vez mais modestos. Não podemos também esquecer do importante fenômeno de favelização que se dá em toda a cidade do Rio de Janeiro e que aparece em Copacabana, nos seus vários morros, de maneira indisfarçável e às vezes ameaçadora. Entre as diversas motivações que foram fonte de atração para o bairro destacam-se os chamados recursos urbanos, desigualmente distribuídos não só pela cidade do Rio de Janeiro, mas pelo país em geral.

A possibilidade de mudança para um estilo de vida mais descontraído, esportivo e ameno também foi importante, na medida em que a "cultura da praia" foi se desenvolvendo, estabelecendo novos padrões de lazer, lúdicos e estéticos. Esse fenômeno não se confinou a Copacabana, produzindo efeitos nas praias e nos bairros que se seguiram, como Ipanema e Leblon. Nestes, apesar de transformações também vigorosas, parece ter havido uma maior preocupação e clareza quanto à necessidade de evitar a perigosa copacabanização. Não se pode esquecer a frase atribuída a Tom Jobim, que teria dito que o Brasil seria feliz "quando todos pudessem morar em Ipanema". Portanto, defrontamo-nos com essa questão que não só divide diferentes atores, mas também os próprios indivíduos que oscilam entre uma postura mais preservacionista, que pode ser rotulada como "elitista", e a outra mais modernizante e invasiva, que pode aparecer como "mais democrática".

Na realidade, aqui estamos nos defrontando com um problema que não é só brasileiro, mas que extrapola as nossas fronteiras, aparecendo como uma questão mundial. Efetivamente, é a partir da temática mais geral das sociedades de massas, ligada ao desenvolvimento do capitalismo, da urbanização, da tecnologia, do transporte, dos meios de comunicação em geral, da mídia etc., que podemos compreender tais processos. Nessa realidade, coloca-se o desafio intelectual e político de como lidar com a memória social e com o patrimônio cultural. Sabemos desde Halbwachs (1976) a importância da organização social do espaço e dos lugares de memória para a construção e a dinâmica de identidades individuais e sociais. A destruição de referências, monumentos, casas, prédios, ruas, cinemas, igrejas, entre outros, tem con- 
seqüências nos mapas emocionais e cognitivos dos habitantes de diferentes tipos de localidades (ver Lins de Barros 1999).

Já em uma outra posição e atitude, estão os que chegam, mais ou menos "outsiders" ou "invasores", destituídos dos laços e das características dos antigos moradores e ávidos por desfrutarem as vantagens de qualidade de vida e de ascensão social propiciadas pelos novos endereços. Assim, estamos lidando, ao examinarmos as políticas públicas de patrimônio, com complexas questões que envolvem emoções, afetos, interesses os mais variados, preferências, gostos e projetos heterogêneos e contraditórios.

Ainda no Rio, a Barra da Tijuca, de ocupação mais recente, tem sido palco e campo de confronto entre interesses e aspirações conflitantes. O famoso plano Lucio Costa, com sábios propósitos de garantir um "crescimento equilibrado" para aquela área, respeitando e protegendo o ambiente natural, já foi diversas vezes atropelado por políticos, empresários de construção civil, condomínios de classe média e invasões promovidas por segmentos menos abonados, com crescimento acelerado de favelas. Mudanças clandestinas, à margem da lei, ou mesmo com cobertura do poder público, desfiguraram o projeto urbanístico original, sempre sob a bandeira do progresso e do desenvolvimento.

Outro exemplo recente no Rio de Janeiro é o das polêmicas Apacs (áreas de proteção do ambiente cultural), que vêm sendo utilizadas pela prefeitura para proteger alguns bairros, como Ipanema, Leblon, Jardim Botânico, de ações que poderiam "descaracterizá-los". Assim, técnicos municipais escolhem, seguindo certos critérios patrimoniais, determinados prédios e casas que devem ser preservados, impedindo a sua derrubada e a construção de edificações que desrespeitariam a memória, agredindo as identidades locais. Nos debates desenvolvidos a respeito dessa iniciativa, falou-se várias vezes da preocupação de impedir mais copacabanizações. A lógica da posição preservacionista é auto-evidente. Os adversários dessas medidas são, mais uma vez, empresários de construção civil em busca de novas obras e lucros, mas também aí se incluem moradores de imóveis protegidos. A posição desses últimos sustenta-se no argumento conhecido por aqueles que lidam com a problemática do patrimônio, o direito de propriedade. Este estaria sendo desrespeitado pela interferência do poder público, cerceando os proprietários e desvalorizando as propriedades.

Nesses bairros surgiu um movimento organizado contra as Apacs, produzindo manifestações e ações na justiça. Por enquanto, tem predominado o ponto de vista da prefeitura. É indiscutível que hoje existe uma maior consciência preservacionista, sobretudo em segmentos mais educados, de nível universitário, influenciados pela gravidade da questão ecológica, ambiental e de qualidade de vida. Eles têm seus representantes no legislativo 
e possuem uma relativa capacidade de pressionar o poder público. Este oscila em um jogo de interesses, em seus diversos níveis, entre atender esses valores e essas expectativas preservacionistas e ceder aos interesses e às motivações de empresas e indivíduos que colocam o mercado como referência básica, associado aos já citados direito de propriedade e liberdade individual.

A posição do cientista social, particularmente do antropólogo, diante desse quadro complexo e conflituoso, não implica necessariamente neutralidade acadêmica. No entanto, é crucial a nossa tarefa de procurar perceber e compreender os diferentes pontos de vista em jogo. Sabemos, pelo menos desde Simmel, que o conflito é fenômeno constitutivo da vida social (ver p.ex. Simmel 1964 e 1971), que percebo como um constante e ininterrupto processo de negociação da realidade, com idas e vindas, recuos e avanços, alianças sendo feitas e desfeitas, projetos adaptando-se e alterando-se, com transformações institucionais e individuais.

A cidade e o seu patrimônio trazem à tona essas questões de interesse para as teorias sociológica e antropológica. A heterogeneidade da sociedade complexa moderno-contemporânea, manifestada dramaticamente nas grandes cidades e nas áreas metropolitanas, aponta para as dificuldades e as limitações de uma ação pública responsável pela defesa e pela proteção de um patrimônio cuja escolha e definição implica necessariamente arbítrio e, em algum nível, exercício do poder. Voltamos à velha questão de saber se sempre há vencedores e perdedores, ou seja, em cada caso e situação é preciso estar atento para procurar avaliar os custos e os ganhos das decisões que são tomadas e dos valores que as sustentam.

Com todas as dificuldades, estou convencido, voltando ao início deste texto, que proteger, tombando o terreiro de Candomblé Casa Branca foi, em função até dos debates e das polêmicas, uma decisão correta em termos de política cultural. Nem sempre temos essa clareza, mas quando isso é possível devemos nos esforçar para compreender, mesmo a posteriori, a complexidade das situações e dos conflitos.

Recebido em 19 de janeiro de 2006

Aprovado em 23 de janeiro de 2006

Gilberto Velho é professor titular e decano do Departamento de Antropologia do Museu Nacional/UFRJ. E-mail: <gvelho@terra.com.br> 


\section{Notas}

${ }^{1}$ Ata da centésima oitava reunião do Conselho Consultivo do Patrimônio Histórico e Artístico Nacional, da Secretaria da Cultura, realizada em 31 de maio de 1984.

${ }^{2}$ Havia sete conselheiros presentes na reunião. Sou o único sobrevivente. Diga-se, de passagem, que na ocasião eu não completara 40 anos, enquanto todos os outros seis colegas tinham mais de 65 anos.

\section{Referências bibliográficas}

GUIMARÃES, Carmen Dora. 2004 [1977]. O homossexual visto por entendidos. Rio de Janeiro: Garamond.

HALBWACHS, Maurice. 1976. Les cadres sociaux de La mémoire. La Haye: Mouton.

LINS DE BARROS, Myriam. 1999. "A cidade dos velhos". In: VELHO, G. (org.), Antropologia urbana-cultura e sociedade no Brasil e em Portugal. Rio de Janeiro: Jorge Zahar. pp. 43-57.

MAGGIE, Yvonne. 1993. Medo do feitiço: relações entre magia e poder no Brasil. Rio de Janeiro: Arquivo Nacional.

SIMMEL, Georg. 1964. Conflict. Translated by Kurt H Wolff. Nova York: The Free Press.

1971. On individuality and social forms. In: LEVINE, D. (org.), Chicago: The University of Chicago Press.

TURNER, Victor. 1974. Dramas, fields and metaphors. Ithaca: Cornell University Press.

VELHO, Gilberto. 1971. “Estigma e comportamento desviante em Copacabana". América Latina, 14(1/2):3-9. 1973. A utopia urbana: um estudo de antropologia social. Rio de Janeiro: Zahar. (org.). 1999. Antropologia urbana: cultura e sociedade no Brasil e em Portugal. Rio de Janeiro: Jorge Zahar. (2a edição: 2002, Jorge Zahar). 1999. "Os mundos de Copacabana". In: Antropologia urbana - cultura e sociedade no Brasil e em Portugal. Rio de Janeiro: Jorge Zahar. pp.11-23. 


\section{Resumo}

O artigo examina a problemática do patrimônio cultural, focalizando o processo de negociação da realidade. Chama a atenção para os aspectos de divergência e conflito a partir de valores e interesses diferenciados dos atores envolvidos. Alguns exemplos são citados, como o tombamento do terreiro de candomblé, Casa Branca, em Salvador, Bahia, e o caso paradigmático de Copacabana. Procura-se mostrar que as políticas públicas de patrimônio não podem ser dissociadas da heterogeneidade e complexidade da vida social.

Palavras-chave: Patrimônio Cultural, Política, Cidade, Heterogeneidade, Conflito

\section{Abstract}

The article examines the issue of cultural heritage, focusing on the process of negotiating reality. It draws attention to aspects of divergence and conflict deriving from the different values and interests of the actors involved. A number of examples are cited - such as the registration of the candomblé terreiro, Casa Blanca, in Salvador, Bahia, and the paradigmatic case of Copacabana - in order to demonstrate that public heritage policies cannot be dissociated from the heterogeneity and complexity of social life.

Key words: Cultural Heritage, Politics, City, Heterogeneity, Conflict 